\title{
The use of the acoustic emission method for the monitoring of changes in the internal structure of polymer-cement mortars when testing the static compressive modulus of elasticity
}

\author{
Dalibor Kocáb ${ }^{1,{ }^{*}}$, Libor Topolá r $^{1}$, Barbara Kucharczyková ${ }^{1}$, Michaela Hoduláková ${ }^{1}$ and \\ Petr Daněk ${ }^{1}$ \\ ${ }^{1}$ Brno University of Technology, Faculty of Civil Engineering, Veveři 331/95, 60200 Brno, \\ Czech Republic
}

\begin{abstract}
The paper focuses on the experimental determination of the dynamic and static compressive modulus of elasticity of selected polymercement mortars and their comparison. The dynamic modulus of elasticity was determined by means of the ultrasonic pulse velocity test and the resonance method. The static compressive modulus of elasticity test was accompanied by a measurement of the material's behaviour using the acoustic emission method, the principle of which is the detection of mechanical dilation waves produced by changes and microscopic faults in the structure of the material. The advantage of the acoustic emission method is the possibility of detecting a crack before it can be found e.g. using a microscope. The outcome of the experiment is a detailed evaluation of the behaviour of polymer-cement mortars made using the values of the elastic modulus and acoustic response of the material during loading.
\end{abstract}

\section{Introduction}

Polymer-cement mortars (PCM) have been used in civil engineering mainly for the purposes of rehabilitation and protection of concrete structures [1]. These composites combine a cement matrix with an organic polymer matrix [2]. The composition of PCMs improves some properties, such as workability, flexural strength, adhesion or chemical resistance [3, 4]. Cement mortars can be modified by a variety of polymers, e.g. latexes, redispersible polymer powders, liquid resins, monomers or acrylic and epoxy emulsions. Polymers can be considered an important component in the manufacturing of modern, sustainable building materials [5].

The suitability of PCMs and the technology of their application are usually given by the technical description of each individual composite. The variety purposes, and therewith connected risk of improper application, can be detrimental to the development of physical and mechanical properties of PCMs, which can in turn endanger the functionality of the rehabilitation system [6]. In order to correctly understand

\footnotetext{
*Corresponding author: dalibor.kocab@,vutbr.cz
} 
the behaviour of a PCM, it is necessary to know its modulus of elasticity as well as its response to loading.

\section{Experiment}

\subsection{Material and specimens}

The specimens were made from two fine-grained polymer-modified mortars based on Portland cement. Tests were performed as part of a pilot experiment, which is why the paper does not include the product designation of the mortars used. For the purposes of evaluation, the composites are identified as "V" and "VII". Specimens of the "V" set were made from a two-component mix - the liquid component is an aqueous copolymer dispersion and the powder component consists of a mixture of Portland cements and mineral fillers. Specimens of set "VII" were made from a single-component powder mix, which comprises silica sand, microfibre and Portland cement, including plasticisers, polymers and the prescribed amount of water.

The fresh PCMs were mixed using a handheld mixer and in keeping with the producer's instructions. Once the components have been mixed, each PCM was made into 6 cylindrical specimens with the nominal diameter of $40 \mathrm{~mm}$ and nominal length of $160 \mathrm{~mm}$ (apart from specimens made for the observation of shrinkage, cf. [7]). The specimens were made for the determination of the dynamic and static modulus of elasticity. For the first three days the specimens were left in their moulds and stored in laboratory conditions with a temperature of $(21 \pm 2){ }^{\circ} \mathrm{C}$ and relative humidity of $(60 \pm 10) \%$, where they were also stored after demoulding. The specimens were not cured during ageing and their surface was intentionally left to dry freely.

\subsection{Testing procedures}

When the specimens reached 28 days of age, all 6 of them were tested for the dynamic modulus of elasticity using two electroacoustic methods - the ultrasonic pulse velocity test and the resonance method. A Pundit PL-200 ultrasonic testing instrument with sensors operating at a frequency of $150 \mathrm{kHz}$ was used to determine the time it takes for an ultrasonic wave to transit along the length of a specimen, see Fig. 1a. Next, the modulus of elasticity $E_{c u}$ was calculated according to the method described in ČSN 731371 [8]. The test cylinders were then tested for the natural frequency of longitudinal, flexural and torsional vibration using a Handyscope HS4 oscilloscope with an acoustic emission (AE) sensor, see Fig. 1b. Dynamic moduli $E_{c r L}$ and $E_{c r f}$ were calculated in accordance with ČSN 731372 [9]. For more details about the dynamic methods used, see e.g. [10].

The static compressive modulus of elasticity $E_{c}$ was determined by means of cyclic loading according to ČSN ISO 1920-10 [11] in a testing press FORM+TEST $200 \mathrm{kN}$. The longitudinal deformations of the specimens were measured by $100 \mathrm{~mm}$ long mechanical strain gauges (Hollan's gauge) with dial indicators (Fig. 2a). The static modulus of elasticity test was completed by gradual increase of compressive stress until specimen failure (Fig. 2b). 
a

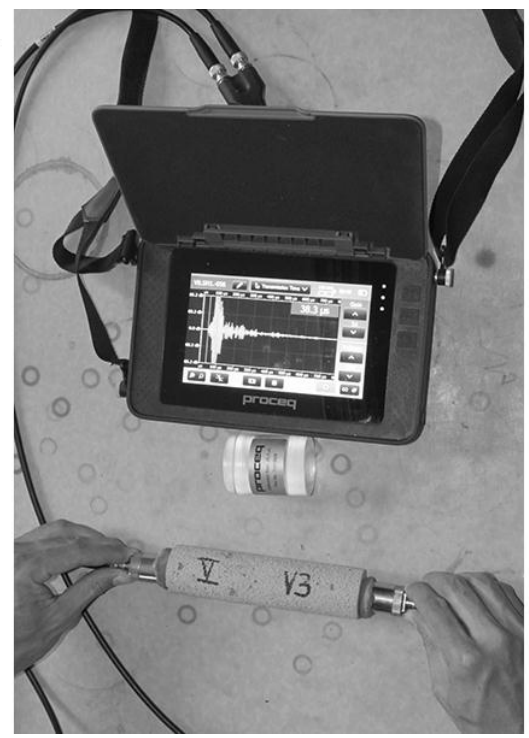

b

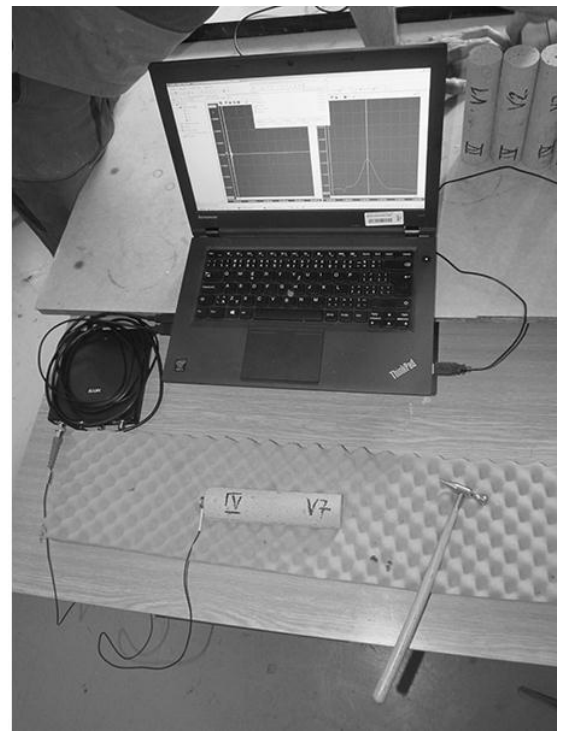

Fig. 1. a) Determination of the time necessary for an ultrasonic pulse to travel through a specimen, b) determination of the natural frequency of a specimen's longitudinal vibration.

$\mathbf{a}$

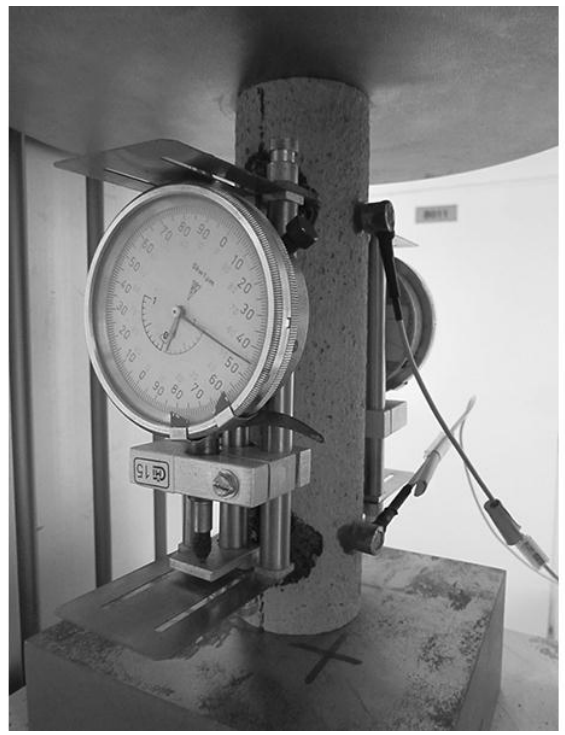

b

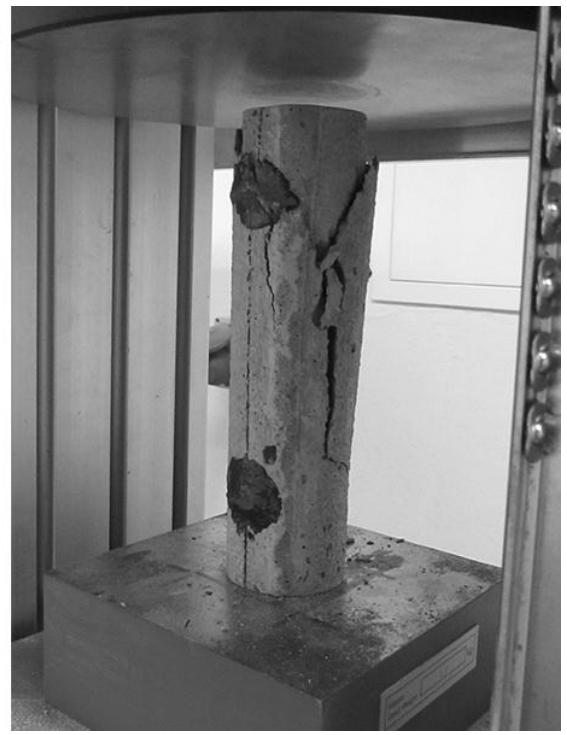

Fig. 2. a) A specimen mounted in a press during the static modulus of elasticity test, b) specimen at the end of the static modulus of elasticity test completed by the determination of compressive strength.

The formation and subsequent propagation of microcracks inside the composite during the cyclic loading test of $E_{c}$ was monitored by the acoustic emission method - a specimen fitted with $\mathrm{AE}$ sensors can be seen in Fig. 2a. Unlike other non-destructive techniques, the $\mathrm{AE}$ method is a passive inspection method capable of examining the entire volume of a structure, structural element or a specimen. An advantage of AE over other defectoscopic methods is the continuous monitoring of an object and lower time requirements compared to the gradual testing made by other methods. However, the AE method is only able to detect active damage, which releases energy inside the body being 
examined in response to stimulation by internal or external stress, as seen in Fig. 3. An AE event is caused by irreversible dislocation and degradation affecting the material's microstructure. The released energy is transformed into a mechanical pulse travelling through the material as a longitudinal or flexural elastic wave. When the wave is detected by an $\mathrm{AE}$ sensor it is converted to an electric signal and is known as an AE signal $[12,13$, 14]. The AE method detects and characterises the development of the damage. It aims to "listen" for acoustic activity emitted by processes taking place inside the material, such as plastic deformation, formation of microstructure, crack initiation and propagation, etc. The AE method is able to detect and evaluate (even localise) the activity of faults and defects as they develop (and only when they develop) [15].

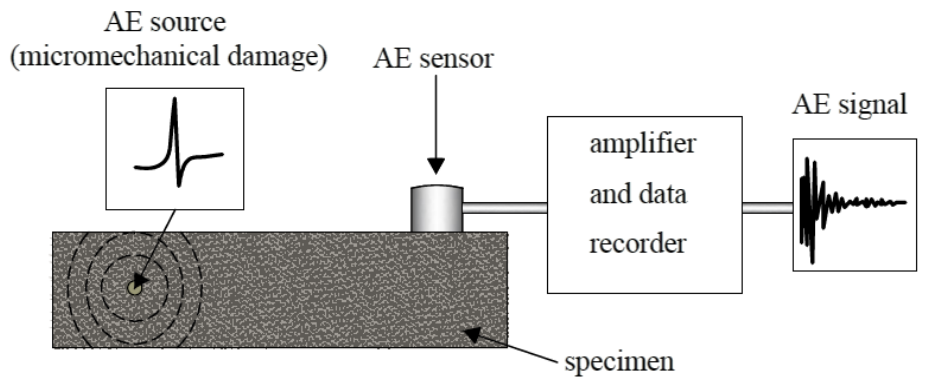

Fig. 3. Principle of acoustic emission measurement [12].

\section{Results and discussion}

\subsection{Elastic modulus}

Table 1 shows the test results for the dynamic moduli of elasticity, the static modulus of elasticity and compressive strength of the two PCMs. The results show that composite "VII" has better strength and elastic properties at the age of examination. This is most clearly visible in the static tests, where value of the static modulus of elasticity of composite "VII" is approx. $5 \mathrm{GPa}$ higher and compressive strength approx. $15 \mathrm{MPa}$ higher than those of composite "V".

\subsection{Acoustic emission}

The chart (Fig. 4) shows the number of AE events that occurred during the test. For clarity, the values are plotted on a logarithmic scale. The chart shows mortar "VII" generated far more AE events during the test, which suggests that a higher number of microcracks had formed than in PCM identified as "V". What is quite interesting is the different trend in the number of events in the two composites during each loading cycle. While mortar "VII" exhibited the Kaiser effect (a sort of "material memory") and the number of AE events occurring during cyclic loading slowly decreased, mortar " $\mathrm{V}$ " saw more AE events during the third cycle than during the second one. Also during loading until failure the two PCMs behaved differently. While the number of events recorded for mortar "VII" during loading until failure was similar to the number recorded during the preloading cycle, mortar "V" produced much more AE events during loading until failure than during previous loading cycles. 
Table 1. Bulk density, elastic moduli and compressive strength of the PCM including average values and sample standard deviations (S. s. d) at the age of 28 days.

\begin{tabular}{|c|c|c|c|c|c|c|}
\hline \multirow{2}{*}{ Specimen } & Bulk density & \multicolumn{3}{|c|}{ Elastic modulus [GPa] } & Compressive strength \\
\cline { 2 - 7 } & $\boldsymbol{D}[\mathbf{m m}]$ & $\boldsymbol{E}_{\boldsymbol{c u}}$ & $\boldsymbol{E}_{\boldsymbol{c r} \boldsymbol{L}}$ & $\boldsymbol{E}_{\boldsymbol{c r f}}$ & $\boldsymbol{E}_{\boldsymbol{c}}$ & $\boldsymbol{f}_{\boldsymbol{c}}$ [MPa] \\
\hline V-1 & 1804 & 20.07 & 17.56 & 17.84 & 13.66 & 32.88 \\
\hline V-2 & 1728 & 17.85 & 15.56 & 15.46 & 12.27 & 31.51 \\
\hline V-3 & 1840 & 20.90 & 18.45 & 18.75 & 13.90 & 33.68 \\
\hline V-4 & 1740 & 18.71 & 16.51 & 16.91 & 14.32 & 29.90 \\
\hline V-5 & 1776 & 19.10 & 16.81 & 16.77 & 12.95 & 32.85 \\
\hline V-6 & 1773 & 19.52 & 17.20 & 17.15 & 13.86 & 34.21 \\
\hline Average: & $\mathbf{1 7 8 0}$ & $\mathbf{1 9 . 4}$ & $\mathbf{1 7 . 0}$ & $\mathbf{1 7 . 1}$ & $\mathbf{1 3 . 5}$ & $\mathbf{3 2 . 5}$ \\
\hline S. s. d.: & $\mathbf{4 1}$ & $\mathbf{1 . 0 7}$ & $\mathbf{0 . 9 8}$ & $\mathbf{1 . 1}$ & $\mathbf{0 . 7 5}$ & $\mathbf{1 . 5 7}$ \\
\hline VII-1 & 1858 & 23.03 & 21.62 & 21.56 & 18.83 & 50.17 \\
\hline VII-2 & 1923 & 23.36 & 22.12 & 22.94 & 18.64 & 50.72 \\
\hline VII-3 & 1796 & 20.73 & 19.24 & 19.08 & 17.19 & 46.32 \\
\hline VII-4 & 1803 & 20.91 & 19.61 & 20.38 & 17.98 & 46.21 \\
\hline VII-5 & 1897 & 22.90 & 21.71 & 21.54 & 18.21 & 47.49 \\
\hline VII-6 & 1823 & 21.12 & 19.22 & 18.90 & 17.00 & 46.89 \\
\hline Average: & $\mathbf{1 8 5 0}$ & $\mathbf{2 2 . 0}$ & $\mathbf{2 0 . 6}$ & $\mathbf{2 0 . 7}$ & $\mathbf{1 8 . 0}$ & $\mathbf{4 8 . 0}$ \\
\hline S. s. d.: & $\mathbf{5 2}$ & $\mathbf{1 . 2 1}$ & $\mathbf{1 . 3 6}$ & $\mathbf{1 . 5 8}$ & $\mathbf{0 . 7 5}$ & $\mathbf{1 . 9 8}$ \\
\hline & & & & & \\
\hline & 179 & \\
\hline
\end{tabular}

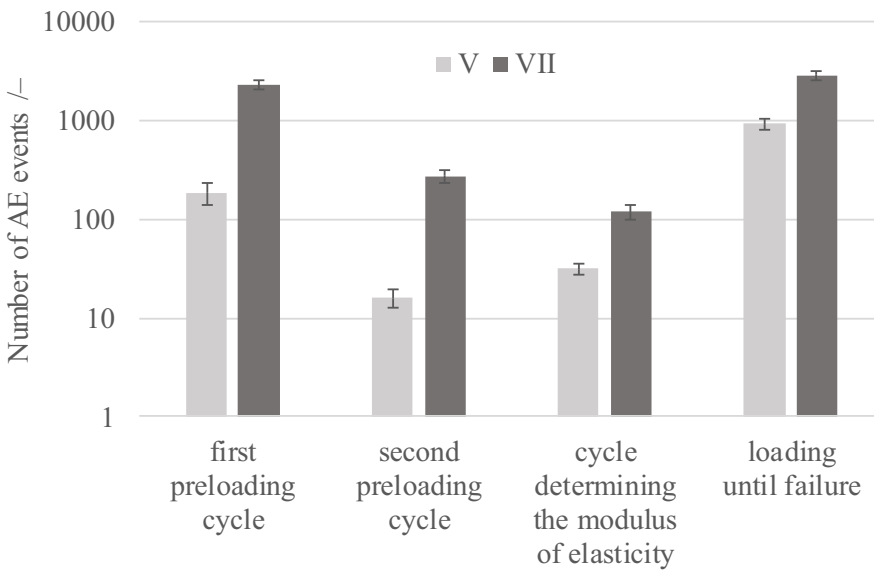

Fig. 4. Number of AE events during the static modulus of elasticity test. 
Given the average amplitude measured during the loading cycles (Fig. 5) as well as the progress of loading until failure, it can be said that microcracks that formed in specimens made from mortar "VII" were of roughly the same size throughout the entire test. On the other hand, the cracks formed in mortar "V" slowly increased in size during cyclic loading.

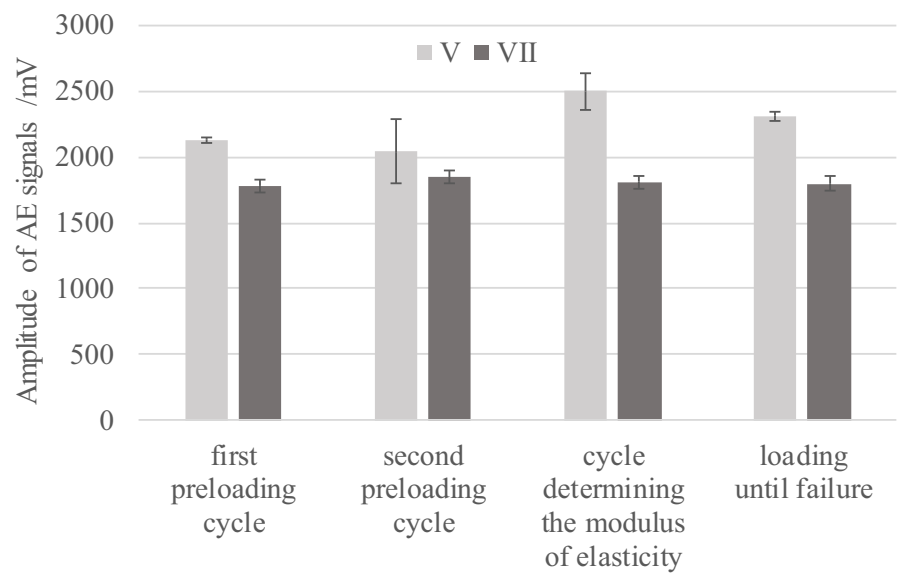

Fig. 5. Amplitude of AE signals during the static modulus of elasticity test.

The energy released by AE signals (Fig. 6) is again plotted on a logarithmic scale. It is clear that the energy released during AE signals was greater in specimens of mortar "VII" than in mortar "V".

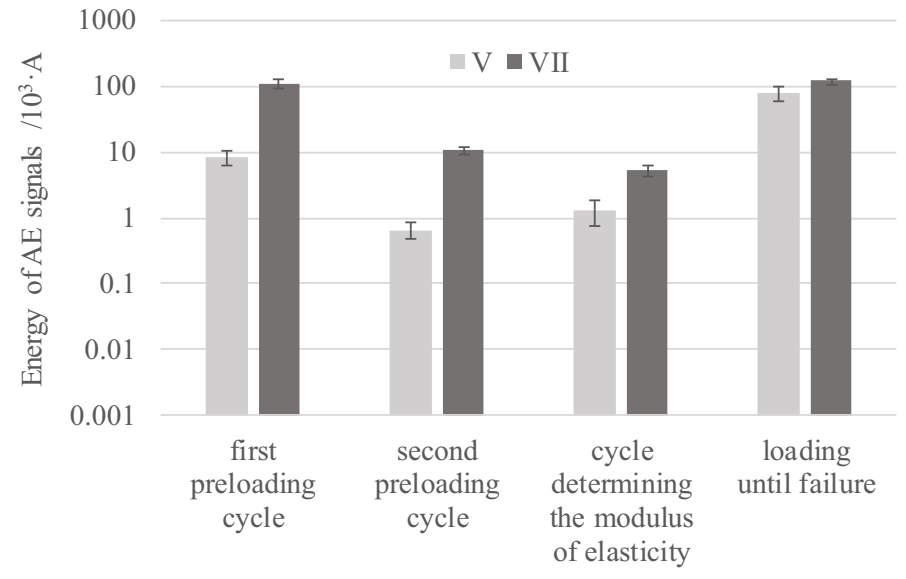

Fig. 6. Energy of AE signals during the static modulus of elasticity test.

\section{Conclusion}

The experiment results show that the PCMs tested herein (designed primarily for concrete rehabilitation) reached lower values of dynamic and static moduli of elasticity (average $E_{c}$ value is only 13.5 GPa in PCM "V" and 18.0 GPa in PCM "VII") than cement-based mortars. PCM are used because of properties other than elastic parameters [1-6]; however, it is still very useful to know the values of their elastic moduli. Polymers, by which the cement mortar is modified, generally have low values of the elastic modulus, which decreases the elastic modulus of the whole composite. The use of PCMs in combination 
with e.g. concrete with a high modulus of elasticity can result in faults caused by the very different values of the elastic modulus.

The presented acoustic emission measurement results show that PCM "VII" suffers from a high number of cracks during loading, however, they are likely small in size. Contrarily, during the loading of PCM "V" a smaller number of larger cracks appears. This material is currently subject to further research.

This paper has been written as a part of project No. 17-14302S „Experimental analysis of the earlyage volume changes in cement-based composites", supported by the GAČR - Czech Science Foundation.

\section{References}

1. W. Malorny, M. Plath, Advanced Materials Research (Trans Tech Publications Ltd, Switzerland, 668, 2013)

2. Y. Ohama, Handbook of polymer-modified concrete and mortars properties and process technology (Noyes Publications, Park Ridge, 1995)

3. P. Łukowski, Materials (MDPI AG, Switzerland, 9, 2016)

4. L. Aggarwal, P. Thapliyal, S. Karade, Construction and Building Materials (Elsevier B.V. 21, 2007)

5. D. Van Gemert, L. Czarnecki, M. Maultzsch, H. Schorn, A. Beeldens, P. Łukowski, E. Knapen, Cement and Concrete Composites (Elsevier B.V. 27, 2005)

6. L. Courard, J. Lenaers, F. Michel, A. Garbacz, Construction and Building Materials (Elsevier B.V. 25, 2011)

7. B. Kucharczyková, H. Šimonová, D. Kocáb, Z. Keršner, Modelování v mechanice (VŠB - TUO, Ostrava, 2017)

8. ČSN 731371 Nedestruktivní zkoušení betonu - Ultrazvuková impulzová metoda zkoušení betonu (2011)

9. ČSN 731372 Nedestruktivní zkoušení betonu - Rezonanční metoda zkoušení betonu (2012)

10. D. Kocáb, M. Králíková, P. Cikrle, P. Misák, B. Kucharczyková, Mater. Technol. (Slovenia, to be published 2017)

11. ČSN ISO 1920-10 Zkoušení betonu - Část 10: Stanoveni statického modulu pružnosi v tlaku (2016)

12. M. Kreidl, R. Šmíd, Technická diagnostika: senzory, metody, analýza signálu (BEN technická literatura, Praha, 2006)

13. V. Malhorta, N. Carino, Handbook on nondestructive testing of concrete (CRC Press, Boca Raton, 2004)

14. M. Matysík, L. Topoláŕ, P. Daněk, H. Šimonová, T. Vymazal, I. Plšková, Advanced Materials Research (Trans Tech Publications Ltd, Switzerland, 1000, 2014)

15. B. Kopec, Nedestruktivní zkoušení materiálů a konstrukcí (CERM, Brno, 2008) 